УДК 686.1.026.23

\title{
СИЛОВИЙ АНАЛІЗ МЕХАНІЗМУ ПРИВОДУ НОЖА ПАПЕРОРІЗАЛЬНОЇ МАШИНИ БР-125
}

๑ С. Л. Панов, к.Т.н., доцент, Р. В. Надточій, магістр, НТУУ «КПІ», Київ, Україна

Разработан метод проведения силового расчета шарнирнорычажного механизма 3-го класса с применением ПО “Maple». Проведен силовой расчет на примере привода ОРМ БР-125. Определены все нагрузки, действующие на звенья механизма.

Developed the method of power analysis of 3rd class articulated lever mechanism using software «Maple». Performed power calculations on the example of the drive mechanism of papercutter

BR-125. Identified all of the loads acting on the chains of the mechanism.

\section{Постановка проблеми}

Силовий аналіз механізмів третього порядку $є$ нетривіальною задачею, оскільки його складно алгоритмізувати. Нині існуючі методи дозволяють розраховувати лише певні окремі типи таких механізмів, не даючи загальної логіки проведення розрахунку.

\section{Аналіз попередніх досліджень}

Силовому аналізу механізмів 3-го класу присвячено багато наукових робіт. Методи розрахунку окремих механізмів проводили Гумільов С. В., Кочетов В. А., проте у вигляді прийнятному до інтеграції в прикладні програми метод був запропонований лише Токмаковим Б. В.

\section{Мета роботи}

Провести силовий аналіз механізму приводу ножа БР-125. Визначити величини сил та моментів сил, що діють на ланки в процесі роботи механізму.

\section{Результати проведених} досліджень

Силовий аналіз проводиться у наступному порядку:

- визначення сил та моментів сил, що діють на механізм.

- розбиття механізму на групи Ассура.

- кінетостатичний розрахунок окремих груп.

На рис. 1 представлено кінематичну схему приводу ножа, розміри ланок $€$ відомими, а їх положення та кінематичні характеристики (лінійні і кутові швидкості та прискорення) були визначені як результат проведення кінематичного розрахунку.

Сили та моменти, що діють на механізм представлені силами інерції, моментами інерції, силами тяжіння та силою різання. Їх визначення $€$ тривіальним та не потребує окремого опису.

Знаючи усі сили, які діють на механізм, маємо змогу провес- 


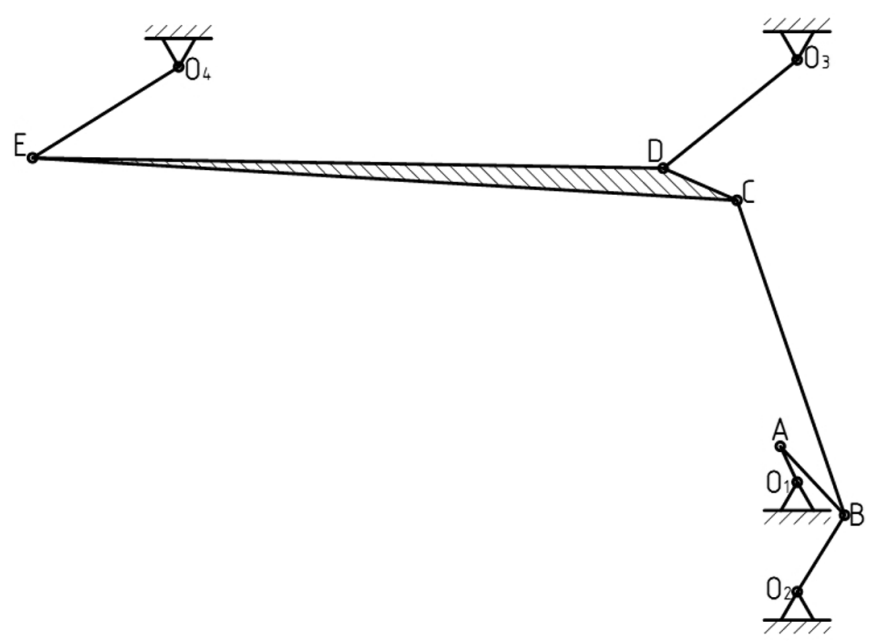

Рис. 1. Кінематична схема механізму привода ножа БР-125

ти кінетостатичний розрахунок, що полягає в наступному: якщо до точок невільної системи разом з зовнішніми силами прикласти уявно фіктивні для цієї системи сили інерції, то сукупність цих сил зрівноважується реакціями зв'язків (принцип Даламбера).

Таким чином маємо можливість перейти від рішення задач динаміки, до статично визначеної системи.

Для силового розрахунку механізм розбивається на групи Aссура [1] і починається 3 останньої групи приєднаної до механізму. У даному випадку усього механізм складається із двох груп. І останньою групою $€$ група № 2 III-го класу, 3-го порядку. На рис. 2 зображено цю групу, а також усі зусилля, що на неї діють.

Методи силового аналізу груп 3-го порядку є недостатньо дослідженими, тому був запропонований власний метод, приведений нижче.
Дослідження проведемо починаючи з поводків (ланок, котрими група приєднується до інших груп, або стійки). Першою розглянемо ланку $\mathrm{O}_{4} \mathrm{E}$. Невідомими є сили реакцій у шарнірах: $\mathrm{R}_{\mathrm{E}}^{\mathrm{O}_{4} \mathrm{E}}$ та $\mathrm{R}_{\mathrm{O}_{4}}$. Верхній індекс в позначенні реакції вказує ланку, на котру діє сила.

Складемо рівняння моментів сил, відносно точок Е та $\mathrm{O}_{4}$ :

$$
\begin{aligned}
& \mathrm{M}_{\mathrm{E}}=\mathrm{EO}_{4} \cdot \underline{\mathrm{R}_{\mathrm{O}_{4}}^{\tau}}+\mathrm{M}_{\mathrm{iH} \cdot \mathrm{O}_{4} \mathrm{E}}+ \\
& +\mathrm{ECM}_{\mathrm{O}_{4} \mathrm{E}} \cdot \mathrm{G}_{\mathrm{O}_{4} \mathrm{E}}^{\tau}+\mathrm{EcM}_{\mathrm{O}_{4} \mathrm{E}} \cdot \\
& \cdot \mathrm{F}_{\mathrm{iH} \cdot \mathrm{O}_{4} \mathrm{E}}^{\tau}=0 ; \\
& \mathrm{M}_{\mathrm{O}_{4}}=\mathrm{EO}_{4} \cdot \underline{\mathrm{R}_{\mathrm{E}}^{\tau \mathrm{O}_{4} \mathrm{E}}}+ \\
& +\mathrm{M}_{\mathrm{iH} \cdot \mathrm{O}_{4} \mathrm{E}}+\mathrm{O}_{3} \mathrm{CM}_{\mathrm{O}_{4} \mathrm{E}} \\
& \cdot \mathrm{G}_{\mathrm{O}_{4} \mathrm{E}}^{\tau}+\mathrm{O}_{3} \mathrm{CM}_{\mathrm{O}_{4} \mathrm{E}} \cdot \\
& \cdot \mathrm{F}_{\mathrm{iH} \cdot \mathrm{O}_{4} \mathrm{E}}^{\tau}=0
\end{aligned}
$$

де $\tau$ у верхньому індексі вказує на те, що мається на увазі складова сили, перпендикулярна до важеля, на довжину котрого вона множиться, а підкреслення вказує на те, що величина невідома. 


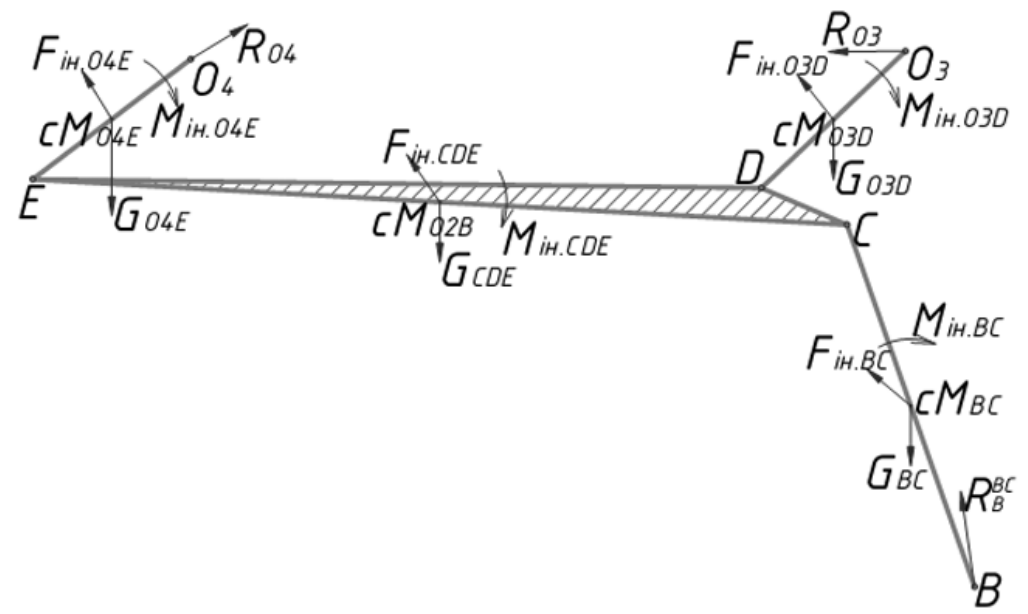

Рис. 2. План сил групи Ассура № 2

Як бачимо, у цих рівняннях невідомими $€$ величини тангенційної складової реакцій в шарнірах, тому можемо їх визначити:

$$
\begin{gathered}
\mathrm{R}_{\mathrm{O}_{4}}^{\tau}=-\frac{\mathrm{M}_{\mathrm{iH} \cdot \mathrm{O}_{4} \mathrm{E}}+\mathrm{EcM}_{\mathrm{O}_{4} \mathrm{E}}+\mathrm{ECM}_{\mathrm{O}_{4} \mathrm{E}} \cdot \mathrm{F}_{\mathrm{iH} \cdot \mathrm{O}_{4} \mathrm{E}}^{\tau} ;}{\mathrm{EO}_{4}} \\
\mathrm{M}_{{\mathrm{iH} \cdot \mathrm{O}_{4} \mathrm{E}}}+\mathrm{O}_{3} \mathrm{cM}_{\mathrm{O}_{4} \mathrm{E}} \cdot \\
\cdot \mathrm{G}_{\mathrm{O}_{4} \mathrm{E}}^{\tau}+\mathrm{O}_{3} \mathrm{CM}_{\mathrm{O}_{4} \mathrm{E}} \cdot \\
\mathrm{R}_{\mathrm{E}}^{\tau \mathrm{O}_{4} \mathrm{E}}=-\frac{\mathrm{F}_{\mathrm{iH} \cdot \mathrm{O}_{4} \mathrm{E}}^{\tau}}{\mathrm{EO}_{4}}
\end{gathered}
$$

Аналогічні дії проводимо 3 поводками $\mathrm{O}_{3} \mathrm{D}$ та $\mathrm{BC}$.

Нормальні складові реакцій в поводках оперуючи лише даними про них визначити неможливо, тому продовжимо аналіз групи дослідженням ланки CDE. Запишемо умову її рівноваги [2] як сумму моментів відносно точок C, D i E.

$$
\begin{aligned}
& \sum \mathrm{M}_{\mathrm{C}}=\mathrm{G}_{\mathrm{CDE}}^{\tau} \cdot \mathrm{CCM}_{\mathrm{CDE}}+ \\
& +\mathrm{F}_{\mathrm{iH} . \mathrm{CDE}}^{\tau} \cdot \mathrm{CCM}_{\mathrm{CDE}}+\mathrm{M}_{\mathrm{iH} . \mathrm{CDE}}+ \\
& +\left(-R_{E}^{\tau \mathrm{O}_{4}}\right)^{\tau} \cdot E C+\left(-\underline{R_{E}^{n \mathrm{O}_{4}}}\right)^{\tau} . \\
& \cdot \mathrm{EC}+\left(-\mathrm{R}_{\mathrm{D}}^{\tau \mathrm{O}_{3} \mathrm{D}}\right)^{\tau} \cdot \mathrm{CD}+
\end{aligned}
$$

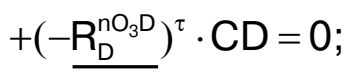

$$
\begin{aligned}
& \sum \mathrm{M}_{\mathrm{D}}=\mathrm{G}_{\mathrm{CDE}}^{\tau} \cdot \mathrm{DCM}_{\mathrm{CDE}}+ \\
& +\mathrm{F}_{\mathrm{iH.CDE}}^{\tau} \cdot \mathrm{DCM}_{\mathrm{CDE}}+\mathrm{M}_{\mathrm{iH.CDE}}+ \\
& \left\{+\left(-\mathrm{R}_{\mathrm{E}}^{\tau \mathrm{O}_{4} \mathrm{E}}\right)^{\tau} \cdot \mathrm{ED}+\left(-\underline{\mathrm{R}_{\mathrm{E}}^{\mathrm{nO}_{4} \mathrm{E}}}\right)^{\tau}\right. \text {. } \\
& \cdot \mathrm{ED}+\left(-\mathrm{R}_{\mathrm{C}}^{\tau \mathrm{BC}}\right)^{\tau} \cdot \mathrm{CD}+ \\
& +\left(-\underline{R}_{\mathrm{C}}^{\mathrm{nBC}}\right)^{\tau} \cdot \mathrm{CD}=0 \text {; } \\
& \sum \mathrm{M}_{\mathrm{E}}=\mathrm{G}_{\mathrm{CDE}}^{\tau} \cdot \mathrm{ECM}_{\mathrm{CDE}}+ \\
& +\mathrm{F}_{\mathrm{iH} . \mathrm{CDE}}^{\tau} \cdot \mathrm{ECM}_{\mathrm{CDE}}+\mathrm{M}_{\mathrm{iH.CDE}}+ \\
& +\left(-\mathrm{R}_{\mathrm{C}}^{\tau \mathrm{BC}}\right)^{\tau} \cdot \mathrm{EC}+\left(-\underline{\mathrm{R}_{\mathrm{C}}^{\mathrm{nBC}}}\right)^{\tau} . \\
& \cdot \mathrm{EC}+\left(-\mathrm{R}_{\mathrm{D}}^{\tau \mathrm{O}_{3} \mathrm{D}}\right)^{\tau} \cdot \mathrm{ED}+ \\
& +\left(-\underline{\mathrm{R}_{\mathrm{D}}^{\mathrm{nO}_{3} \mathrm{D}}}\right)^{\tau} \cdot E \mathrm{ED}=0 \text {; }
\end{aligned}
$$


ки - вони направлені вздовж відповідних поводків. Користуючись рівнянням прямої, що проходить через дві точки [3] задамо ці напрямки і додамо до системи:

$$
\begin{aligned}
& \left(\left(\mathrm{Ey}-\mathrm{O}_{4} \mathrm{y}\right) \cdot \underline{\mathrm{Rx}_{\mathrm{E}}^{\mathrm{nO}_{4} \mathrm{E}}}+\right. \\
& +\left(\mathrm{O}_{4} \mathrm{x}-\mathrm{Ex}\right) \cdot \underline{\mathrm{Ry}_{\mathrm{E}}^{\mathrm{nO}_{4} \mathrm{E}}}+ \\
& +\left(\mathrm{Ex} \cdot \mathrm{O}_{4} \mathrm{y}-\mathrm{O}_{4} \mathrm{x} \cdot \mathrm{Ey}\right)=0 \text {; } \\
& \left(\mathrm{Dy}-\mathrm{O}_{3} \mathrm{y}\right) \cdot \mathrm{Rx}_{\mathrm{D}}^{\mathrm{nO} \mathrm{O}_{3} \mathrm{D}}+ \\
& +\left(\mathrm{O}_{3} \mathrm{x}-\mathrm{Dx}\right) \cdot \mathrm{Ry}_{\mathrm{D}}^{\mathrm{nO}_{3} \mathrm{D}}+ \\
& +\left(D x \cdot O_{3} y-\overline{O_{3} x \cdot D y}\right)=0 \text {; } \\
& (\mathrm{Cy}-\mathrm{By}) \cdot \underline{\mathrm{Rx}_{\mathrm{C}}^{\mathrm{nBC}}}+ \\
& +(\mathrm{Bx}-\mathrm{Cx}) \cdot \underline{\mathrm{Ry}_{\mathrm{C}}^{\mathrm{nBC}}}+ \\
& +(C x \cdot B y-B x \cdot C y)=0 \text {. }
\end{aligned}
$$

Об'єднавши ці дві системи рівнянь, отримаємо визначену систему, що дає нам змогу вирахувати реакції в шарнірах $\mathrm{C}, \mathrm{D}$ і Е. Такі системи легко вирішуються 3 застосуванням програмного пакету Maple.

Таким чином силовий аналіз групи проведений та визначено усі сили та реакції, що на неї діють. Для групи Ассура № 1 (IIй клас, 2-й порядок) було застосовано звичайний метод дослідження, відомий з курсу теорії машин та механізмів, тому розглядати цю групу немає необхідності.

\section{Висновки}

В ході дослідження була розроблена методика проведення силового аналізу механізму приводу ножа одноножевої паперорізальної машини БР-125 і було створено прикладну програму для його розрахунку. Силовий аналіз таких механізмів $є$ складною задачею і важко піддається алгоритмізації, тому загальної методології його проведення немає. Методи, що наведені в даній роботі, є оригінальними і представлені у вигляді програми, написаної на мові програмування, прикладного пакету «Maple 13» із застосуванням його можливостей щодо математичних обрахунків. Результати дослідження можуть бути корисними інженерам при проектуванні нових механізмів, а також студентам і аспірантам в науковій роботі.

1. Кореняко А. С. Курсовое проектирование по теории механизмов и машин / А. С. Кореняко, Л. И. Кременштейн, С. Д. Петровский, Г. М. Овсиенко, В. Е. Баханов, П. М. Емец. - К. : Вища школа, 1970. - 332 с. 2. Тынкевич М. А. Численные методы анализа / М. А. Тынкевич. - Кемерово, 2002. - 184 с. 3. Кочин Н. Е. Векторное исчисление и начала тензорного исчисления / Н. Е. Кочин. - М. : Наука, 1965. - 424 с.

1. Korenjako A. S. Kursovoe proektirovanie po teorii mehanizmov i mashin / A. S. Korenjako, L. I. Kremenshtejn, S. D. Petrovskij, G. M. Ovsienko, V. E. Bahanov, P. M. Emec. - K. : Vishha shkola, 1970. - 332 s. 2. Tynkevich M. A. Chislennye metody analiza / M. A. Tynkevich. - Kemerovo, 2002. 184 s. 3. Kochin N. E. Vektornoe ischislenie i nachala tenzornogo ischislenija / N. E. Kochin. - M. : Nauka, 1965. - 424 s.

$$
\text { Рецензент - Ю. О. Шостачук, к.Т.н., }
$$
доцент, НТУУ «КП|»

Надійшла до редакції 18.06.13 